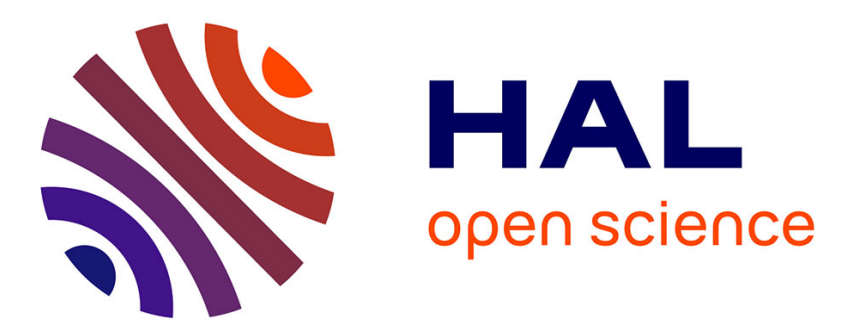

\title{
Stability of above-ground and below-ground processes to extreme drought in model grassland ecosystems: Interactions with plant species diversity and soil nitrogen availability.
}

\author{
Juliette Bloor, R.D. Bardgett
}

\section{To cite this version:}

Juliette Bloor, R.D. Bardgett. Stability of above-ground and below-ground processes to extreme drought in model grassland ecosystems: Interactions with plant species diversity and soil nitrogen availability.. Perspectives in Plant Ecology, Evolution and Systematics, 2012, 14 (3), pp.193-204. 10.1016/j.ppees.2011.12.001 . hal-02649087

\section{HAL Id: hal-02649087 \\ https://hal.inrae.fr/hal-02649087}

Submitted on 29 May 2020

HAL is a multi-disciplinary open access archive for the deposit and dissemination of scientific research documents, whether they are published or not. The documents may come from teaching and research institutions in France or abroad, or from public or private research centers.
L'archive ouverte pluridisciplinaire HAL, est destinée au dépôt et à la diffusion de documents scientifiques de niveau recherche, publiés ou non, émanant des établissements d'enseignement et de recherche français ou étrangers, des laboratoires publics ou privés. 
Research article

\title{
Stability of above-ground and below-ground processes to extreme drought in model grassland ecosystems: Interactions with plant species diversity and soil nitrogen availability
}

\author{
Juliette M.G. Bloor ${ }^{\mathrm{a}, *}$, Richard D. Bardgett ${ }^{\mathrm{b}}$ \\ a INRA, UR874-Grassland Ecosystem Research Unit, 234 Avenue du Brézet, F-63100 Clermont-Ferrand, France \\ ${ }^{\mathrm{b}}$ Soil and Ecosystem Ecology Laboratory, Lancaster Environment Centre, Lancaster University, Lancaster LA1 4YQ UK
}

\section{A R T I C L E I N F O}

\section{Article history:}

Received 12 July 2011

Received in revised form

29 November 2011

Accepted 2 December 2011

\section{Keywords:}

Climate change

$\mathrm{CO}_{2}$ fluxes

Ecosystem services

Plant-soil interactions

Productivity

Soil fertility

\begin{abstract}
A B S T R A C T
Extreme drought events have the potential to cause dramatic changes in ecosystem structure and function, but the controls upon ecosystem stability to drought remain poorly understood. Here we used model systems of two commonly occurring, temperate grassland communities to investigate the shortterm interactive effects of a simulated 100-year summer drought event, soil nitrogen $(\mathrm{N})$ availability and plant species diversity (low/high) on key ecosystem processes related to carbon (C) and $\mathrm{N}$ cycling. Whole ecosystem $\mathrm{CO}_{2}$ fluxes and leaching losses were recorded during drought and post-rewetting. Litter decomposition and $\mathrm{C} / \mathrm{N}$ stocks in vegetation, soil and soil microbes were assessed 4 weeks after the end of drought. Experimental drought caused strong reductions in ecosystem respiration and net ecosystem $\mathrm{CO}_{2}$ exchange, but ecosystem fluxes recovered rapidly following rewetting irrespective of $\mathrm{N}$ and species diversity. As expected, root $C$ stocks and litter decomposition were adversely affected by drought across all $\mathrm{N}$ and plant diversity treatments. In contrast, drought increased soil water retention, organic nutrient leaching losses and soil fertility. Drought responses of above-ground vegetation $C$ stocks varied depending on plant diversity, with greater stability of above-ground vegetation $C$ to drought in the high versus low diversity treatment. This positive effect of high plant diversity on above-ground vegetation C stability coincided with a decrease in the stability of microbial biomass $\mathrm{C}$. Unlike species diversity, soil $\mathrm{N}$ availability had limited effects on the stability of ecosystem processes to extreme drought. Overall, our findings indicate that extreme drought events promote post-drought soil nutrient retention and soil fertility, with cascading effects on ecosystem $C$ fixation rates. Data on above-ground ecosystem processes underline the importance of species diversity for grassland function in a changing environment. Furthermore, our results suggest that plant-soil interactions play a key role for the short-term stability of above-ground vegetation $\mathrm{C}$ storage to extreme drought events.
\end{abstract}

(c) 2011 Elsevier GmbH. All rights reserved.

\section{Introduction}

Mounting evidence suggests that ongoing climate change will result in an increase in the frequency of extreme weather events or climate anomalies such as unusually dry years (IPCC, 2007). Such extreme climatic events have the potential to cause dramatic changes in ecosystem structure and function via non-linear threshold dynamics, and are expected to be equally, if not more important than ecosystem responses to changes in mean temperature or precipitation (Easterling et al., 2000; Jentsch et al., 2007; Smith, 2011). However, impacts of extreme weather events (determined as a

\footnotetext{
* Corresponding author. Tel.: +33 4736244 25; fax: +33 473624457 .

E-mail address: juliette.bloor@clermont.inra.fr (J.M.G. Bloor).
}

statistical extremity with respect to a historical reference period) have received far less attention compared with gradual climatic changes, and knowledge of how extreme weather affects ecosystem services is lacking (Jentsch et al., 2007; Smith, 2011).

Grassland responses to extreme drought events are of particular interest because precipitation regimes are known to be critical in determining grassland types, productivity and decomposition rates (Laurenroth and Sala, 1992; Knapp and Smith, 2001). In general, grasslands subjected to severe drought show a decrease in leaf-level photosynthesis, plant productivity, and an increase in carbon (C) allocation to roots, although the magnitude and duration of drought responses differ across studies (Kahmen et al., 2005; Kreyling et al., 2008; Gilgen and Buchmann, 2009; St. Clair et al., 2009; Jentsch et al., 2011). Drought also has feedback effects on the soil nitrogen $(\mathrm{N})$ pool since the microbial processes that 
regulate soil $\mathrm{N}$ availability are sensitive to short-term variations in soil moisture. For example, increased duration and intensity of drought are usually associated with decreasing $\mathrm{N}$ mineralisation and inorganic $\mathrm{N}$ fluxes (Borken and Matzner, 2009). This interdependence between precipitation and soil $\mathrm{N}$ availability is further strengthened because inorganic $\mathrm{N}$ is dissolved in soil solution, and water/rainfall affects its mobility and loss. Rewetting at the end of drought typically results in a short-term pulse of $\mathrm{C}$ and $\mathrm{N}$ mineralisation, and increased risks of nutrient leaching losses (Fierer and Schimel, 2002; Gordon et al., 2008). In contrast, longer-term effects of rewetting on microbial activity are more variable and may be driven by changes in microbial community composition (Schimel et al., 2007). Consequently the size and fluxes of the soil $\mathrm{N}$ pool are largely determined by precipitation events, and precipitation anomalies may have a large impact on $\mathrm{C}$ and $\mathrm{N}$ cycling at a variety of temporal scales (Verburg et al., 2009).

Predicting grassland responses to drought events requires an understanding of the complex interplay between abiotic and biotic factors which determine ecosystem stability. For example, high soil $\mathrm{N}$ availability could increase ecosystem vulnerability to drought via: (i) greater plant water demand in high biomass systems which reduces soil moisture (Wang et al., 2007); (ii) root:shoot allocation patterns adapted to competition for light rather than below-ground resource acquisition (Tilman, 1990); (iii) short-lived plant organs and higher rates of nutrient turnover which lower plant resistance (MacGillivray et al., 1995). However, complementarity in wateruse in diverse, multi-species communities may partly offset water stress during drought periods (De Boeck et al., 2006). Consequently, impacts of soil $\mathrm{N}$ availability on ecosystem stability could vary depending on plant community composition. Furthermore, it has long been suggested that communities which are more diverse in species or functional groups have greater stability against environmental perturbations (diversity-stability hypothesis, reviewed in Johnson et al., 1996; Hooper et al., 2005). In theory, redundancy of functionally similar species or compensation by better-adapted species may buffer ecosystem processes in diverse communities under changing conditions (Hooper et al., 2005). In practice, studies examining the relationship between species diversity and the stability of ecosystem processes to drought have yielded conflicting results (Pfisterer and Schmid, 2002; Van Peer et al., 2004; Kahmen et al., 2005; Wang et al., 2007; Kreyling et al., 2008). To date, interactions between soil $\mathrm{N}$ and plant species diversity on ecosystem stability to drought have yet to be tested.

Here we use an outdoor mesocosm experiment to examine short-term above-ground and below-ground grassland responses to a simulated 100-year extreme summer drought event. In order to better understand the consequences of extreme events in natural systems, we chose two temperate grassland communities that are widespread across Europe, but have contrasting levels of species richness, as a model system. The primary objective of this study was to determine the interactive effects of drought, soil $\mathrm{N}$ availability and plant community composition on key ecosystem processes related to $\mathrm{C}$ and $\mathrm{N}$ cycling (ecosystem $\mathrm{CO}_{2}$ exchange rates, $\mathrm{C} / \mathrm{N}$ soil leaching losses, litter decomposition rates, $\mathrm{C} / \mathrm{N}$ storage in vegetation, soil and soil microbes). We focused on short-term drought responses to increase the detection of possible shifts in plant-soil interactions following drying-rewetting events (Hodge et al., 2000; Schimel et al., 2007). Specifically, we hypothesized that: (i) extreme drought has a negative impact on plant $C$ storage and soil nutrient retention during rewetting; (ii) high soil $\mathrm{N}$ availability reduces ecosystem stability to drought, i.e. more negative drought effects in high $\mathrm{N}$ treatments versus low $\mathrm{N}$ treatments; (iii) plant communities with high plant diversity have greater stability to extreme drought, i.e. non-significant or less negative drought effects in highdiversity communities versus low-diversity communities; (iv) high plant species diversity mitigates effects of high soil $\mathrm{N}$ availability on ecosystem vulnerability to drought.

\section{Materials and methods}

\section{Experimental design}

The mesocosm experiment was conducted at the Lancaster University Field Station, UK $\left(54^{\circ} 1^{\prime} \mathrm{N}, 2^{\circ} 46^{\prime} \mathrm{W}, 94 \mathrm{~m}\right.$ a.s.l.), and comprised of three treatments in a fully factorial design: soil nutrient availability (low N, high $\mathrm{N}$ ), plant species diversity (low, high), and rainfall (ambient, extreme drought event). Each of the eight treatment combinations was replicated five times, resulting in a total of 40 experimental mesocosms.

Mesocosms were established outdoors in September 2009; high density polypropylene pots $(38 \mathrm{~cm} \times 38 \mathrm{~cm} \times 40 \mathrm{~cm})$ with drainage holes were packed with a 8 -cm layer of limestone chippings for improved drainage, followed by a $27-\mathrm{cm}$ layer of topsoil $\left(\mathrm{pH}_{\mathrm{H} 2 \mathrm{O}}\right.$ of $6.3,0.25 \% \mathrm{~N}, 3.05 \% \mathrm{C}$ ) collected from a sandy loam pasture at the study site. Prior to pot-filling, the experimental soil was homogenized by mixing, and visible stones and roots were removed by hand. To generate the high $\mathrm{N}$ treatment, we added $27 \mathrm{~g}$ of dried, finely cut $(1 \mathrm{~mm})$ Trifolium repens shoots $(4.5 \% \mathrm{~N}, 10.1 \mathrm{C}: \mathrm{N})$ to the $0-5 \mathrm{~cm}$ soil layer of each mesocosm (equivalent to $1.22 \mathrm{~g} \mathrm{~N}$ per mesocosm or $84.5 \mathrm{~kg} \mathrm{~N} \mathrm{ha}^{-1}$ ). We used fresh organic material rather than inorganic fertilizer in the nutrient treatment as it provides a more realistic simulation of soil nutrient variability in natural ecosystems (Maestre and Reynolds, 2007). The organic material was thoroughly mixed with background soil (6.51) before filling the $0-5 \mathrm{~cm}$ layer. Added organic material resulted in an increase in soil C from 3.05 to $3.1 \%$ per mesocosm, and was considered to have little impact on the soil water- or nutrient-holding capacity over the course of the study. In the low $\mathrm{N}$ treatment, no organic material was added to the mesocosms.

Two experimental grassland communities with contrasting levels of plant species diversity were established in the mesocosms based on assemblages classified as Anthoxanthum odoratumGeranium sylvaticum (MG3) and Lolium perenne-Cynosurus cristatus (MG6) by the UK National Vegetation Classification (Rodwell, 1998). Both community types comprised of common grassland species (including grasses, forbs and a legume species). The low diversity treatment (MG6 model) consisted of six species (Cyanosurus christatus L.; Holcus lanatus L.; Lolium perenne L.; Cerastium fontanum L.; Trifolium repens L.; Festuca rubra L.), whereas the high diversity treatment (MG3 model) consisted of 11 species (C. christatus; H. lanatus; L. perenne; C. fontanum; T. repens; F. rubra; Agrostis capillaris L.; Anthoxanthum odoratum L.; Plantago lanceolata L.; Poa trivialis L.; Dactylis glomerata L.). These levels of species richness are consistent with species numbers found in $40 \mathrm{~cm} \times 40 \mathrm{~cm}$ quadrats in the field, i.e. quadrats equivalent to the size of the mesocosms in this study (J.M.G. Bloor, unpublished data). Experimental plants were grown from seed obtained from Emorsgate Seeds (Kings Lynn, UK) and germinated at room temperature in trays filled with compost (Scotts Levington M3 Professional Growing Medium). Newly established seedlings ( $<3$ weeks old) were transplanted individually into plug trays filled with experimental soil and maintained in a glasshouse at Lancaster University. One week prior to planting in the mesocosms, plug trays with seedlings were put outside at the field site to acclimatize; at the time of planting (25th September 2009), all seedlings were $6-8$ weeks old.

Thirty six seedlings were transplanted into each mesocosm; planting positions for each species were allocated at random, but the same planting grid pattern was maintained across mesocosms by using a wire grid secured to the top of the pots. Planting densities were consistent with species abundance patterns observed in 
MG3 and MG6 communities (Supplementary Material, Table S1), and ensured almost identical species evenness in the two diversity treatments at the start of the experiment $(E=0.98$ and 0.97 in the low and high-diversity treatments, respectively). Mesocosms were watered regularly for 2 weeks to ensure successful seedling establishment. Plant communities were then left to grow under natural rainfall conditions. At the end of April 2010, above-ground vegetation in each mesocosm was clipped to $5 \mathrm{~cm}$ above the soil surface, and plants were left to re-grow.

The extreme drought event applied in the drought treatment was defined as the 100-year recurrence event for drought during the vegetation growing season, i.e. the number of consecutive days with less than $1 \mathrm{~mm}$ daily precipitation. Precipitation amounts $<1 \mathrm{~mm}$ are generally intercepted by the canopy and do not recharge soil water content (De Boeck et al., 2011). Long-term weather records for the field site (1967-2008) were used to fit a Gumbel I distribution to the annual extremes of drought duration for the local vegetation growing period (April-September). The 100year recurrence event corresponded to a drought period of 34 days, which was applied from 11 June until 15 July in the peak growing season.

Drought was simulated using $2 \mathrm{~m} \times 1.5 \mathrm{~m}$ rain-out shelters constructed with a sloping wooden frame and covered with clear polythene sheet (light transmission 90\%). During drought manipulation, mesocosms were arranged in a split-plot design with 10 blocks (each block comprising all nutrient $\times$ plant diversity treatment combinations); rain-out shelters were applied to 5 blocks assigned to the drought treatment at random. Shelters were placed at a minimum height of $50 \mathrm{~cm}$ above the pots to allow near-surface air exchange, and were only maintained over the pots/blocks during rainy weather conditions to minimize treatment artefacts. No significant temperature difference was observed under rain-out shelters during rain manipulation periods ( $T$-test between hourly mean temperatures inside and outside the shelters, $P>0.1$ ). Soil moisture content was monitored using an SM200 probe coupled to a HH2 moisture meter (Delta-T Devices, Cambridge, England). Drought manipulation resulted in a deficit of $88.4 \mathrm{~mm}$ rainfall for mesocosms in the experimental drought treatment (Fig. 1). At the end of the experimental drought period, vegetation die-back was assessed based on 100 point quadrats per mesocosm; $61.1 \pm 1.6 \%$ senescence was recorded across droughted mesocosms compared with $10.6 \pm 1.2 \%$ senescence across control mesocosms.

At the end of drought manipulation, rewetting occurred rapidly as a result of natural rainfall $(17.9 \mathrm{~mm})$ in the night of 15 th-16th July. All mesocosms were left to grow under natural rainfall conditions before final harvest in mid-August.

\section{Litter decomposition assay}

Root and leaf material for the decomposition assay were collected from monocultures of Dactylis glomerata and Festuca rubra grown under field conditions in central France $\left(45^{\circ} 38^{\prime} \mathrm{N}, 2^{\circ} 44^{\prime} \mathrm{E}\right)$. Techniques for obtaining root litter are problematic because: (i) there is no evidence that roots senesce and are shed discretely the way that leaves do; and (ii) published methods for collecting dead roots do not control for the stage of decomposition (Hobbie et al., 2010). Consequently we used dried, fresh roots to compare with leaf litter in our decomposition assay following Hobbie et al. (2010). Root material was collected following destruction of 1-year-old monocultures in 2008 (R. Pilon, unpublished data). Senescent leaf litter was collected from 2-year-old monocultures at the start of 2010; leaf material was yellow and considered to be recently senesced (Austin et al., 2009). Litter from each species was dried $\left(60^{\circ} \mathrm{C}\right.$ for $\left.48 \mathrm{~h}\right)$, finely cut $(1 \mathrm{~mm})$, and combined in a $1: 1 \mathrm{mix}$ to produce standardised litter $(1.5 \% \mathrm{~N}, 44.6 \% \mathrm{C}, 5.7 \%$ lignin versus $1.7 \%$ N, $40.6 \%$ C, $16.6 \%$ lignin for leaf and root litter, respectively).

Litterbags for both leaf and root material were constructed using $5 \mathrm{~cm} \times 5 \mathrm{~cm}$ ANKOM F57 polyester/polyethylene filter bags $(25 \mu \mathrm{m}$ mesh; ANKOM Technology, Macedon, NY, USA). Pre-weighed litterbags were filled with weighed, dried plant material (mean litter weight: $0.5089 \pm 0.005 \mathrm{~g}$ ) and bag edges were heat-sealed. Two bags of each litter type were incorporated into the $0-5 \mathrm{~cm}$ soil layer in each mesocosm immediately prior to the start of the drought event (8-9th June 2010), resulting in a total of 240 litter bags. All bags were retrieved at the end of the experiment (12th August 2010). Once retrieved, litterbags were carefully cleaned and dried $\left(60^{\circ} \mathrm{C}, 48 \mathrm{~h}\right)$ before being weighed for determination of mass loss. Given the relatively short incubation period, this assay focuses on the initial phases of litter decomposition dominated by leaching processes and mineralisation of soluble compounds contained in litter.

\section{$\mathrm{CO}_{2}$ fluxes}

Measurement of $\mathrm{CO}_{2}$ fluxes was made on six dates from June through to August 2010: immediately prior to start of the drought event (10 June), midway through the drought event (24 June), at the end of the drought event ( 14 July), and at three time points postrewetting (23rd July, 29th July, 8th August). Flux measurements were made using custom-made chambers constructed with Ariel Liteglaze acrylic sheet (92\% light transmission) fixed onto an 8-cm high polypropylene base (total chamber volume of $0.05 \mathrm{~m}^{3}$ ). Chambers were sealed onto the rim of mesocosms with a rubberised strip during sampling, and enclosed the vegetation with minimal disturbance. On each sampling date, flux measurements were made between $11: 30 \mathrm{~h}$ and $14: 30 \mathrm{~h}$ in the afternoon using a portable IRGA EGM-4 (PP Systems, Herts, UK) attached to the chambers using silicone tubing and quick-release clips. Net ecosystem $\mathrm{CO}_{2}-\mathrm{C}$ fluxes were measured with the transparent chamber, whereas ecosystem respiration was measured using a black-out bag to convert the equipment to a dark chamber (Ward et al., 2009); at each gas sampling, chamber closure time was $2 \mathrm{~min}$. In order to complete flux measurements during the mid-day period, measurements were made on 4 of the 5 replicates per experimental treatment, chosen at random for each measurement campaign.

\section{Leachate $C$ and $N$}

From June through to the end of the experimental period, mesocosms were placed on individual saucers (each supported on two breeze blocks) and drainage water was collected in $250 \mathrm{ml}$ bottles via a funnel attached to the perforated bottom corner of each saucer, following De Deyn et al. (2009). The area between the saucers and the mesocosms was sealed with plastic to prevent direct rainfall into the saucers. Collection pots placed under mesocosms during the drought period indicated no water seepage from the droughted mesocosms throughout drought manipulation. Leachate was collected/analysed from all mesocosms at three rainfall events post-rewetting to assess the impact of drought on post-drought nutrient losses (17th July, 25th July, 4th August). It was not possible to record total leachate losses over the entire post-rewetting period due to a number of high-intensity, nighttime rainfall events which caused collecting pots to overflow.

After collection, leachates were filtered through Whatman No. 1 filter paper and kept cool $\left(5^{\circ} \mathrm{C}\right)$ prior to chemical analysis (within 5 days). Leachates were analysed for dissolved organic carbon (DOC) using a Shimadzu 5000A TOC analyser. Total N was determined by oxidation with potassium persulphate $\left(\mathrm{K}_{2} \mathrm{~S}_{2} \mathrm{O}_{8}\right)$ following Ross (1992), and the resultant ammonium and nitrate was 


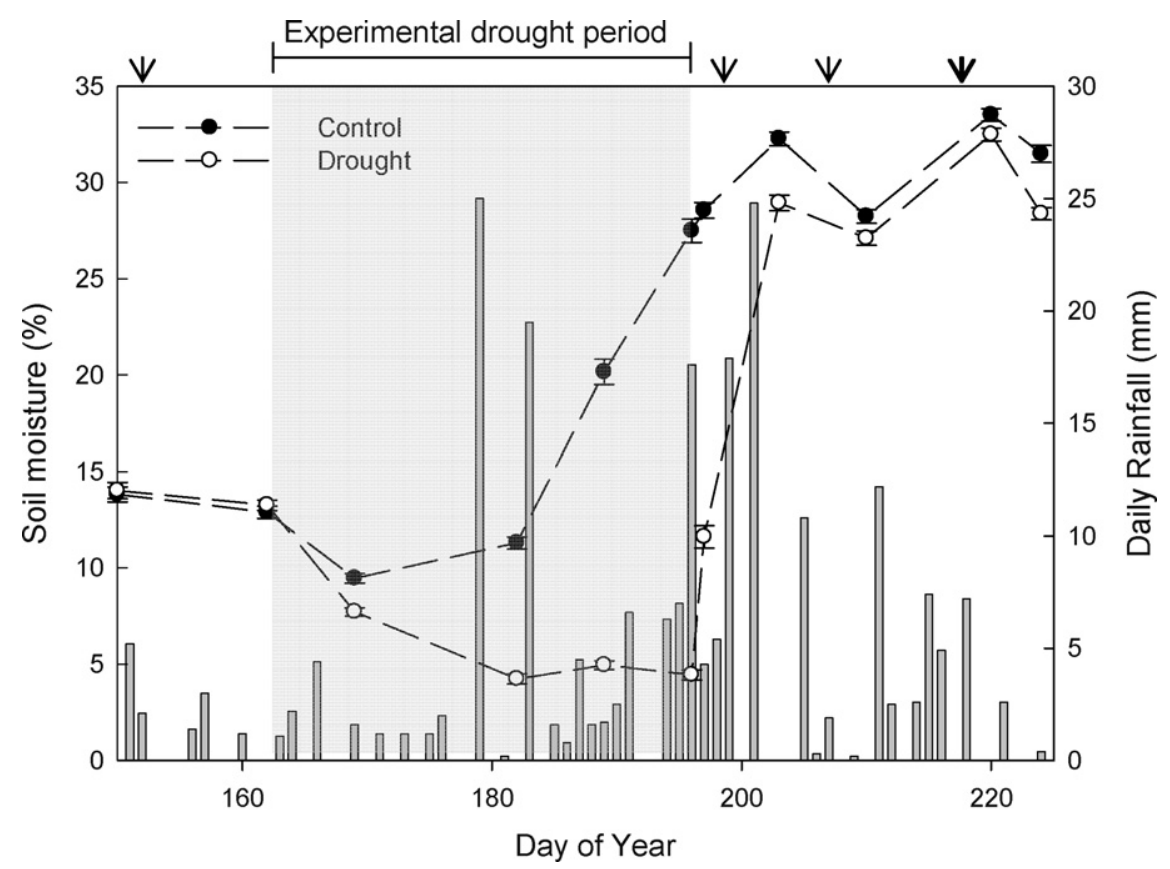

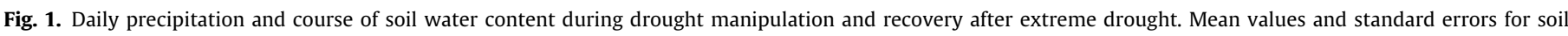
moisture in control and droughted mesocosms are given $(n=20)$. Timing of leachate collection is indicated by arrows.

measured using colorimetry and autoanalyser procedures (Bran \& Luebbe, Norderstedt, Germany). Dissolved inorganic nitrogen (DIN) was measured directly by autoanalyser procedures and dissolved organic nitrogen (DON) was calculated by subtracting DIN from the total $\mathrm{N}$ measured. Loss of $\mathrm{N}$ and $\mathrm{C}$ was determined from the volume of leachate and the concentrations of $\mathrm{N}$ and $\mathrm{C}$ at each sampling.

\section{Plant and soil measurements at final harvest}

Above-ground and below-ground vegetation was harvested on the 12th August ( 4 weeks after the end of the experimental drought period), in line with local grassland hay cutting dates in dry years. Above-ground plant material was collected by clipping all shoot material to $5 \mathrm{~cm}$. In addition, a subsample of plant stubble $(0-5 \mathrm{~cm})$ was collected from each mesocosm by clipping a randomly positioned $15 \mathrm{~cm} \times 20 \mathrm{~cm}$ quadrat to soil level. Above-ground biomass samples were then dried at $60^{\circ} \mathrm{C}$ for $48 \mathrm{~h}$ prior to weighing. Belowground biomass was determined using five intact soil cores $(3.4 \mathrm{~cm}$ diameter, $0-15 \mathrm{~cm}$ deep) per mesocosm, collected immediately after plant clipping. Soil bulk density was determined using the dry weight of soil contained in the volume of one of the soil cores chosen at random. The remaining four soil cores were sieved ( $2 \mathrm{~mm}$ mesh) to separate roots from soil. Root samples were washed, dried at $60^{\circ} \mathrm{C}$ for $48 \mathrm{~h}$ and weighed. Total $\mathrm{C}$ and $\mathrm{N}$ content in aboveground biomass and root samples were determined for $5 \mathrm{mg}$ of finely ground material (Brinkmann ball grinder, Retsch, MM200) using an elemental combustion analyzer (Flash EA 1112 CNS analyzer, ThermoFinnigan, Milan, Italy). Vegetation $\mathrm{C}$ and $\mathrm{N}$ pools per mesocosm were expressed on a $\mathrm{m}^{2}$ basis by extrapolating from the sampled area.

Soil mineral $\mathrm{N}$ was extracted from a sub-sample of freshly sieved soil $(2 \mathrm{~mm}$ ) by shaking $5 \mathrm{~g}$ of soil with $25 \mathrm{ml} 1 \mathrm{M} \mathrm{KCl}$ for $1 \mathrm{~h}$ on an orbital shaker. The $\mathrm{KCl}$ extracts were filtered through Whatman No. 1 filters and analysed for ammonium and nitrate by autoanalyser procedures. Additional soil samples were oven-dried $\left(105^{\circ} \mathrm{C}, 24 \mathrm{~h}\right)$ to determine gravimetric moisture content. In addition, potential net $\mathrm{N}$ mineralisation rate was measured as the release of mineral $\mathrm{N}$ after incubation of $5 \mathrm{~g}$ soil samples in the laboratory (10 days, $22^{\circ} \mathrm{C}$ ); after incubation, soil samples were extracted with $\mathrm{KCl}$ as previously described.

Microbial biomass $\mathrm{N}$ and $\mathrm{C}$ were measured on $5 \mathrm{~g}$ subsamples of freshly sieved soil using the chloroform fumigation-incubation method (Brookes et al., 1985). Soluble C was extracted from fumigated and unfumigated samples with $25 \mathrm{~mL}$ of $0.5 \mathrm{M} \mathrm{K}_{2} \mathrm{SO}_{4}$ solution. Microbial $\mathrm{C}\left(C_{\mathrm{mic}}\right)$ was calculated as the difference in total $C$ extracted in fumigated and unfumigated soils, with $k_{\mathrm{C}}=0.35$ as the adjustment factor (Sparling et al., 1990). Extractable $\mathrm{N}$ in the above extracts was determined by oxidation with $\mathrm{K}_{2} \mathrm{~S}_{2} \mathrm{O}_{8}$, as described for leachates. Microbial $\mathrm{N}\left(N_{\text {mic }}\right)$ was calculated as the difference in total $\mathrm{N}$ extracted in fumigated and unfumigated soils, with $k_{\mathrm{N}}=0.54$ as the adjustment factor (Brookes et al., 1985).

\section{Data analyses}

The magnitude and direction of above-ground and belowground drought responses were used as an indicator of short-term ecosystem stability to drought, following Jentsch et al. (2011). Given that our objective was to examine overall stability to drought, we did not distinguish between resistance and resilience metrics as in some other studies (Wardle et al., 2000; Van Ruijven and Berendse, 2010). The experiment was analysed as a splitplot design following Zar (1998), with drought treatment as the whole-plot factor, fixed and among blocks, and both $\mathrm{N}$ and plant diversity treatments as fixed sub-plot factors within blocks. Differences between treatments were determined with Tukey post-hoc tests. All statistical analysis was carried out using Statgraphics Plus 4.1 (Statistical Graphics Corp., Rockville, Maryland, USA). Where necessary, data were transformed prior to analysis to conform with assumptions of normality and homogeneity of variances.

\section{Results}

\section{Climate}

Comparisons with long-term meterological observations at the field site (1967-2008) indicated that rainfall during the growing 

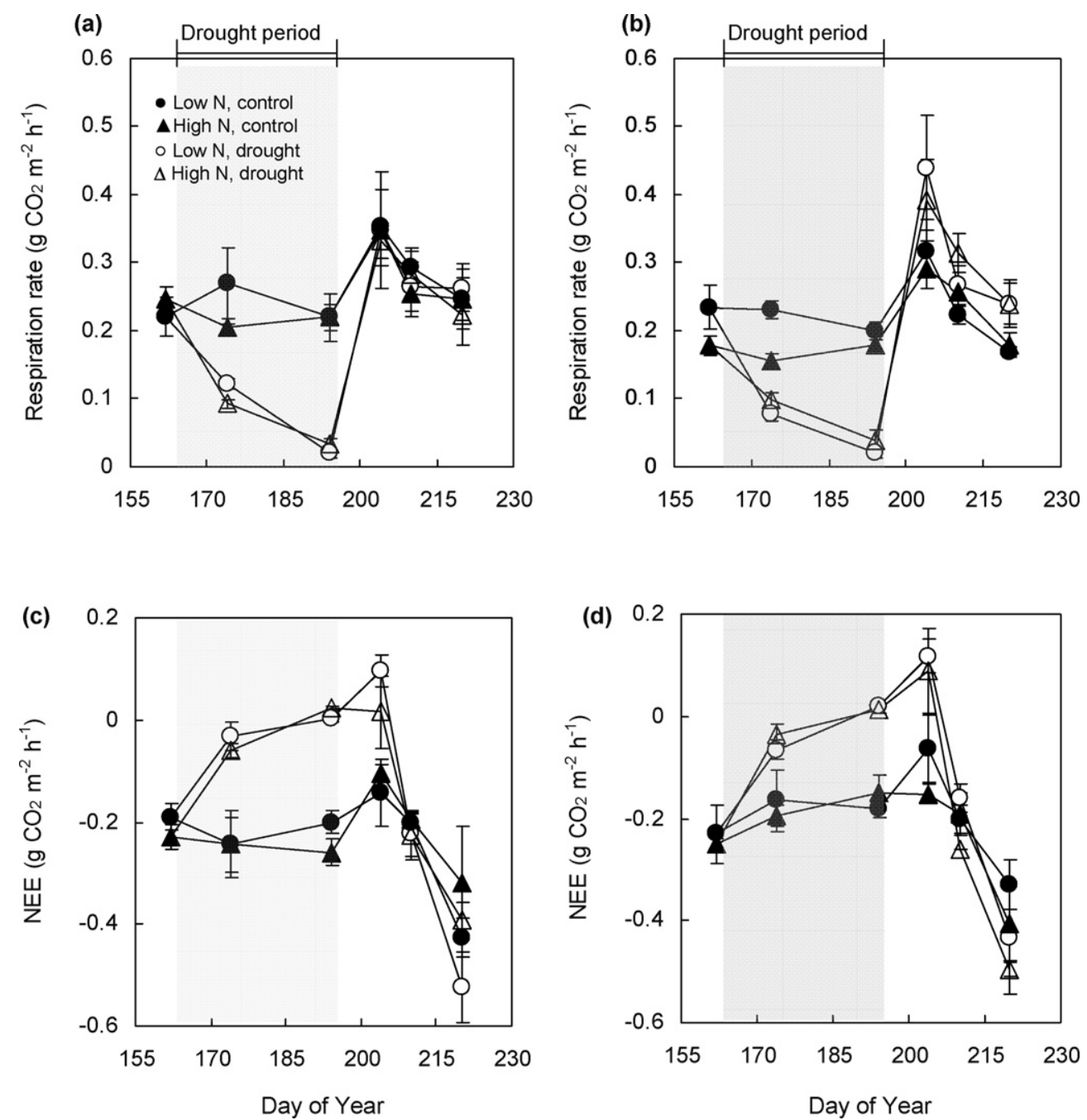

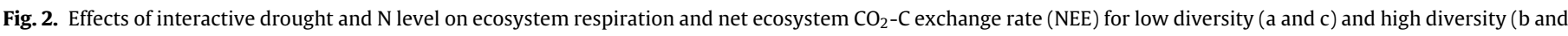
d) mesocosms during the experimental period. Means ( \pm 1 standard error) are shown; $n=4$.

season of 2010 was close to the long term average $(400.6 \mathrm{~mm}$ in 2010 versus $384 \mathrm{~mm}$ ). Below-average rainfall in spring was compensated for by above-average rainfall in July. The 2009-2010 winter period was cooler than the long-term average (mean monthly temperature $2.3^{\circ} \mathrm{C}$ versus $4.4^{\circ} \mathrm{C}$ ), but temperatures during the 2010 growing season were equal to the long term average (mean monthly temperature $12.5^{\circ} \mathrm{C}$ ).

\section{Soil moisture during drought and drought recovery}

During drought manipulation, patterns of soil moisture content differed significantly between droughted and non-droughted mesocosms across $\mathrm{N}$ and plant diversity treatments (Fig. 1). Soil moisture content in the non-droughted mesocosms was relatively low at the start of the drought period due to dry conditions, but increased dramatically in the latter half of the drought period due to heavy rainfall events (Fig. 1). In contrast, droughted mesocosms decreased to a minimum soil water content ( $\sim 4 \%$ soil moisture) and remained at this level until rewetting (Fig. 1). During the 'drought recovery' period, i.e. post-rewetting, non-droughted mesocosms approached field capacity (35\% soil moisture) and soil moisture remained high due to regular rain events (Fig. 1). Above-average rainfall in the week following rewetting resulted in a rapid convergence of soil moisture levels in droughted and non-droughted mesocosms (Fig. 1). Nevertheless, the drought treatment was associated with significantly lower soil moisture throughout the recovery period (Fig. $1, P<0.05$ for all measurement dates). Drought-induced reductions in soil moisture showed few interactions with plant species diversity or $\mathrm{N}$ treatment throughout the experimental period. However, in the latter half of the drought period, low $\mathrm{N}$ conditions were associated with greater drought-induced reductions in soil moisture (drought $\times \mathrm{N}$ interaction, $F_{1,23}=6.75, P<0.05$ ).

\section{$\mathrm{CO}_{2}$ fluxes during drought and drought recovery}

Over the course of the drought period, droughted mesocosms showed a significant decrease in respiration rates $\left(R_{\text {eco }}\right)$ and net ecosystem $\mathrm{CO}_{2}-\mathrm{C}$ exchange (NEE), indicating less net $\mathrm{C}$ fixation across all nutrient and plant diversity treatments (Fig. 2). Twelve days after the start of experimental drought, drought-induced reductions in $R_{\text {eco }}$ were significantly greater in low $\mathrm{N}$ mesocosms compared with high $\mathrm{N}$ mesocosms (Table 1, Fig. 2). Furthermore, drought-induced decreases in net $\mathrm{C}$ fixation were significantly greater in the low-compared to high-diversity treatment (Table 1 , Fig. 2). At the end of the drought period, both $R_{\text {eco }}$ and NEE were close to zero in all droughted mesocosms (Fig. 2). The magnitude of drought-induced reductions in $R_{\text {eco }}$ did not differ depending 
Table 1

Ecosystem respiration and net ecosystem $\mathrm{CO}_{2}-\mathrm{C}$ exchange rate (NEE) as a function of drought, $\mathrm{N}$ level and species diversity treatment during extreme drought and drought recovery (post-rewetting). $F$ values derived from analysis of variance are shown: significant effects $(P<0.05)$ are shown bold type.

\begin{tabular}{|c|c|c|c|c|c|}
\hline & \multicolumn{2}{|l|}{ Drought } & \multicolumn{3}{|c|}{ Post-rewetting } \\
\hline & Day 12 & Day 32 & Day 7 & Day 14 & Day 24 \\
\hline \multicolumn{6}{|l|}{ (a) Ecosystem respiration } \\
\hline Drought (D) & 43.46 & 7996.6 & 0.86 & 0.68 & 0.83 \\
\hline $\mathrm{N}$ level $(\mathrm{N})$ & 7.96 & 0.85 & 0.67 & 0.30 & 0.32 \\
\hline Species diversity $(\mathrm{S})$ & 5.98 & 0.01 & 0.27 & 0.48 & 0.04 \\
\hline $\mathrm{D} \times \mathrm{N}$ & 5.98 & 2.29 & 0.07 & 1.30 & 0.13 \\
\hline $\mathrm{D} \times \mathrm{S}$ & 0.88 & 0.10 & 4.47 & 1.19 & 5.45 \\
\hline $\mathrm{N} \times \mathrm{S}$ & 0.57 & 0.54 & 0.23 & 0.48 & 0.01 \\
\hline $\mathrm{D} \times \mathrm{N} \times \mathrm{S}$ & 1.27 & 1.51 & 0.01 & 0.09 & 0.01 \\
\hline \multicolumn{6}{|l|}{ (b) NEE } \\
\hline Drought (D) & 8.14 & 38.71 & 15.35 & 0.71 & 9.86 \\
\hline $\mathrm{N}$ level $(\mathrm{N})$ & 0.28 & 1.51 & 1.75 & 0.49 & 2.25 \\
\hline Species diversity $(\mathrm{S})$ & 4.52 & 9.60 & 1.16 & 0.04 & 0.55 \\
\hline $\mathrm{D} \times \mathrm{N}$ & 0.38 & 2.21 & 0.21 & 1.46 & 0.02 \\
\hline $\mathrm{D} \times \mathrm{S}$ & 5.72 & 6.90 & 0.29 & 0.58 & 1.25 \\
\hline $\mathrm{N} \times \mathrm{S}$ & 0.28 & 2.23 & 0.39 & 0.91 & 0.02 \\
\hline $\mathrm{D} \times \mathrm{N} \times \mathrm{S}$ & 2.27 & 5.44 & 2.22 & 0.15 & 1.01 \\
\hline
\end{tabular}

$\mathrm{DF}_{1,18}$ for all terms except drought $\left(\mathrm{DF}_{1,6}\right) ; n=4$.

on plant diversity or $\mathrm{N}$ treatment (Table 1, Fig. 2). In contrast, effects of drought on NEE were stronger in the low diversity compared to the high diversity treatment, these drought-induced reductions in net $\mathrm{C}$ fixation being exacerbated by high $\mathrm{N}$ (Table 1 , Fig. 2).

Patterns of recovery of $R_{\text {eco }}$ following re-wetting were fast irrespective of $\mathrm{N}$ and plant diversity treatment (Fig. 2). In the low plant diversity treatment, droughted and non-droughted mesocosms showed no difference in $R_{\text {eco }}$ from day 7 onwards of the drought-recovery period. In the high plant diversity treatment, drought was associated with an increase in respiration rates on days 7 and 24 after re-wetting (Table 1, Fig. 2). Recovery of NEE after drought was slower than $R_{\text {eco }} ; 1$ week after re-wetting, drought was associated with net $C$ efflux (NEE $>0$ ) across all plant diversity and $\mathrm{N}$ treatment combinations (Table 1, Fig. 2). Nevertheless, complete recovery of NEE to a $C$ sink was observed 2 weeks after rewetting (no significant drought effects, Table 1). By the end of the measurement period (day 24 after re-wetting), $C$ fixation rates were higher for droughted mesocosms compared with non-droughted controls, irrespective of $\mathrm{N}$ and plant diversity treatment (Fig. 2).

\section{Post-drought leaching losses of $C$ and $N$}

Leaching losses recorded after rewetting were ranked DOC $>$ DON $>$ DIN across all treatments (Fig. 3). Nutrient losses varied with time, but losses of both DOC and DON were generally lower in droughted mesocosms throughout the drought-recovery period (Table 2, Fig. 3). Unlike DOC/DON losses, responses of DIN losses to drought varied depending on $\mathrm{N}$ and species diversity across sampling dates (Table 2, Fig. 3).

Two days after rewetting, leaching losses of both $\mathrm{C}$ and $\mathrm{N}$ showed a significant nutrient $\times$ drought interaction (Fig. 2; $F_{1,23}=4.43, P<0.05$ for DOC, $F_{1,23}=9.33$ and $F_{1,23}=10.85$ for DON and DIN, respectively, $P<0.01$ ). Under low $\mathrm{N}$ conditions, drought was associated with a decrease in DOC, DON and DIN losses, whereas under high $\mathrm{N}$, drought was associated with an increase in DIN losses and no change in DOC or DON (Fig. 3). Ten days after rewetting, DOC losses were significantly lower from all pots subjected to experimental drought $\left(F_{1,23}=5.43, P<0.05\right)$, whereas DON showed only marginally significant decreases in response to drought (Fig. 3). Twenty days after rewetting, both DOC and DON still showed significantly lower values in the drought treatment,

\section{Table 2}

Effects of drought, $\mathrm{N}$ level, species diversity treatment and time on drainage water and nutrient leaching (DOC, DON, DIN) during grassland recovery after extreme drought. $F$ values derived from analysis of variance are shown: significant effects $(P<0.05)$ are shown bold type.

\begin{tabular}{lcrrr}
\hline \multirow{2}{*}{ Effect } & \multicolumn{3}{l}{ Variables } & \\
\cline { 2 - 5 } & Drainage water & DOC & DON & DIN \\
\hline Drought (D) & $\mathbf{9 . 9 7}$ & $\mathbf{5 . 9 3}$ & $\mathbf{9 . 8 4}$ & 0.60 \\
N level (N) & 0.28 & 0.18 & 0.01 & 2.29 \\
Species diversity (S) & 1.66 & 0.98 & 0.35 & 0.62 \\
Time (T) & $\mathbf{3 9 . 0 9}$ & $\mathbf{1 4 8 . 7 7}$ & $\mathbf{8 0 . 7 1}$ & $\mathbf{3 3 . 7 0}$ \\
$\mathrm{D} \times \mathrm{N}$ & 2.43 & 0.09 & 2.49 & 1.45 \\
$\mathrm{D} \times \mathrm{S}$ & 1.29 & 0.36 & 0.89 & 1.61 \\
$\mathrm{~N} \times \mathrm{S}$ & 0.01 & 0.56 & 0.97 & 0.81 \\
$\mathrm{D} \times \mathrm{T}$ & 2.19 & 2.42 & 0.82 & 0.03 \\
$\mathrm{~S} \times \mathrm{T}$ & 1.03 & 0.26 & 0.74 & 0.06 \\
$\mathrm{~N} \times \mathrm{T}$ & 2.83 & 2.46 & $\mathbf{3 . 5 7}$ & 1.28 \\
$\mathrm{D} \times \mathrm{N} \times \mathrm{S}$ & 0.90 & 0.77 & 2.01 & $\mathbf{6 . 7 0}$ \\
$\mathrm{D} \times \mathrm{N} \times \mathrm{T}$ & 1.42 & 0.70 & 0.69 & $\mathbf{3 . 9 6}$ \\
$\mathrm{D} \times \mathrm{S} \times \mathrm{T}$ & 0.30 & 0.71 & 0.94 & 0.22 \\
$\mathrm{~N} \times \mathrm{S} \times \mathrm{T}$ & 1.91 & 0.46 & 1.00 & 0.51 \\
$\mathrm{D} \times \mathrm{N} \times \mathrm{S} \times \mathrm{T}$ & 0.57 & 0.43 & 1.97 & 0.73 \\
\hline
\end{tabular}

$\mathrm{DF}_{85}$ for all terms except drought $\left(\mathrm{DF}_{8}\right) ; n=5$.

irrespective of $\mathrm{N}$ and plant diversity treatment $\left(F_{1,23}=5.66\right.$ and $F_{1,23}=9.69$, respectively, $\left.P<0.05\right)$. DIN losses showed no response to drought, nutrients or plant diversity at days 10 and 20 after re-wetting (Fig. 3).

Effects of drought on leaching losses were driven by changes in volumes of drainage water rather than leachate concentration; irrespective of measurement date, the volume of drained leachate was lower in the drought treatment compared to the ambient rainfall treatment (Table 2, Fig. 3). Furthermore, volume of drainage water showed a significant nutrient $\times$ drought interaction 2 days after rewetting $\left(F_{1,23}=10.77, P<0.01\right)$, with greater drought-induced reductions in drainage water volume under low $\mathrm{N}$ conditions. Leachate concentration only showed a significant effect of drought for DOC and DIN collected 2 days after rewetting; DOC concentration showed a significant increase with drought $\left(F_{1,8}=10.64\right.$, $P<0.05)$, whereas DIN concentration decreased under droughted, low $\mathrm{N}$ conditions but increased under droughted, high $\mathrm{N}$ conditions (significant $\mathrm{N} \times$ drought interaction, $F_{1,23}=6.70, P<0.05$ ). No other treatment effects were detected on leachate concentrations at any date. Interestingly, volumes of leachate and DOC/DON leaching losses recorded in the drought treatment 20 days after re-wetting showed a significant negative correlation with aboveground plant biomass measured at the end of the study $(r=-0.62$, -0.64 and -0.69 , respectively, $P<0.01$ in all cases). Neither volume of drainage water nor leaching losses showed any relationship with green biomass at the end of the study for ambient rainfall mesocosms.

\section{Effects of drought on litter decomposition}

Irrespective of experimental treatment, leaf litter decomposed more rapidly than root litter over the 2-month incubation period (32.2\% versus $19.9 \%$ for leaf and root litter, respectively; Supplementary Material Table S2). Across litter types, drought had a significant negative effect on decomposition rate during the initial stage of decomposition, but drought-induced reductions in decomposition were greater for leaf litter than for root litter (Supplementary Material Table S2; Fig. 4). Neither plant diversity nor $\mathrm{N}$ treatment affected decomposition rates of the two litter types (Supplementary Material Table S2). 

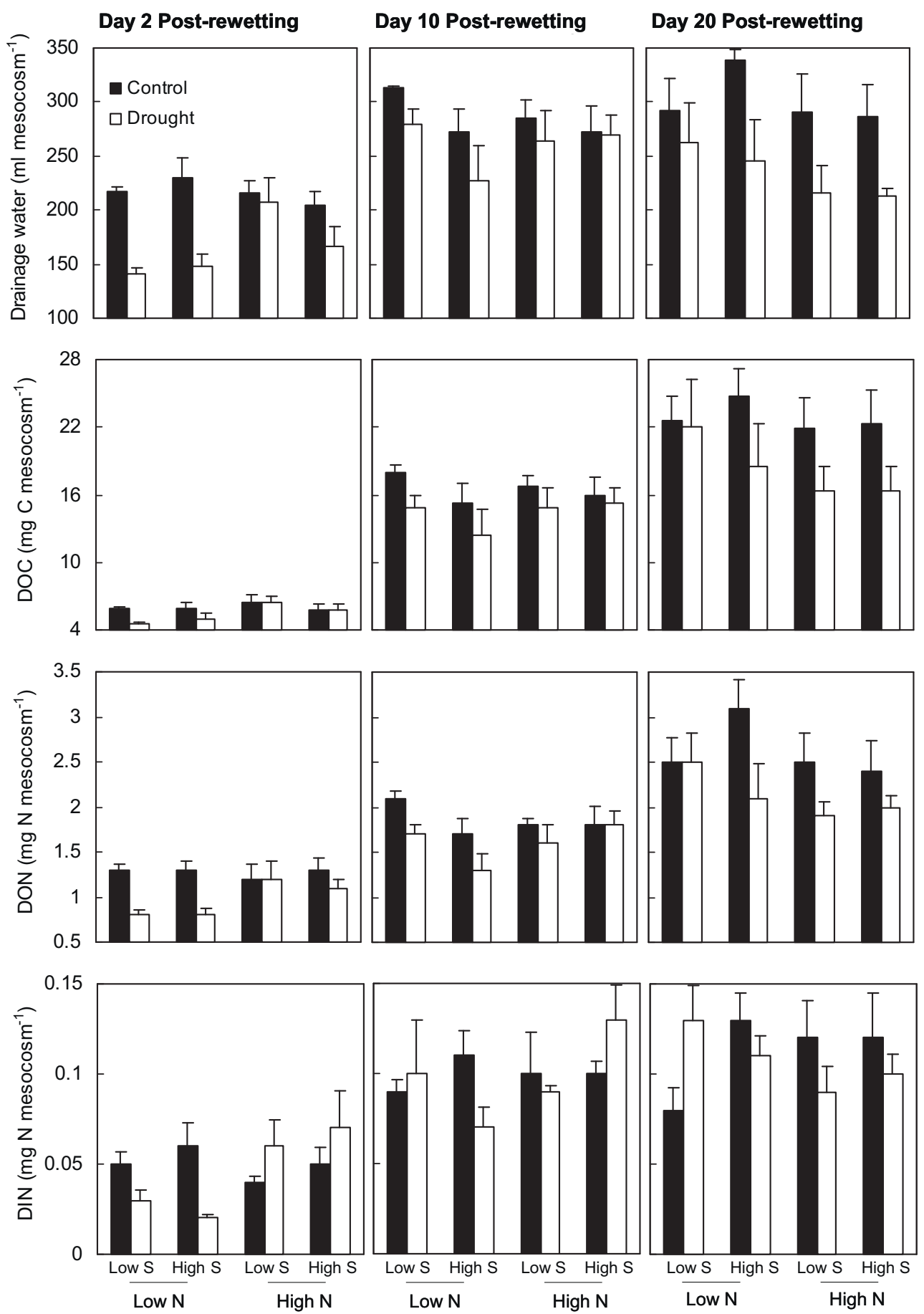

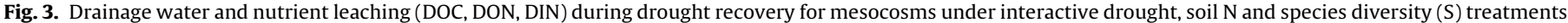
Means and standard errors are presented $(n=5)$.

\section{$C$ and $N$ in vegetation and soil pools at final harvest}

At final harvest, total above-ground standing biomass ranged from 344.1 to $541.7 \mathrm{~g}$ and below-ground biomass in the $0-15 \mathrm{~cm}$ soil layer ranged from 212 to $402 \mathrm{~g}$ across experimental treatments. Experimental drought had a significant negative effect on the mass of $\mathrm{C}$ in roots across all plant diversity and $\mathrm{N}$ treatments (Table 3 ). In contrast, effects of drought on aboveground vegetation $\mathrm{C}$ varied depending on species diversity; in low plant diversity mesocosms, above-ground $\mathrm{C}$ showed a negative response to drought, whereas in high plant diversity mesocosms, above-ground $C$ showed no change in response to drought (Table 3, Fig. 5). Microbial responses to drought also varied depending on plant diversity treatment (Table 4). In low diversity mesocosms, both $C_{\text {mic }}$ and $N_{\text {mic }}$ showed a positive response to drought, whereas in high diversity mesocosms, drought was associated with a decrease in $C_{\text {mic }}$ and $N_{\text {mic }}$ (Fig. 6). Consequently, drought response in above-ground vegetation $C$ was negatively correlated with $C_{\text {mic }}$ drought response $(r=-0.68$, $P<0.01)$. 


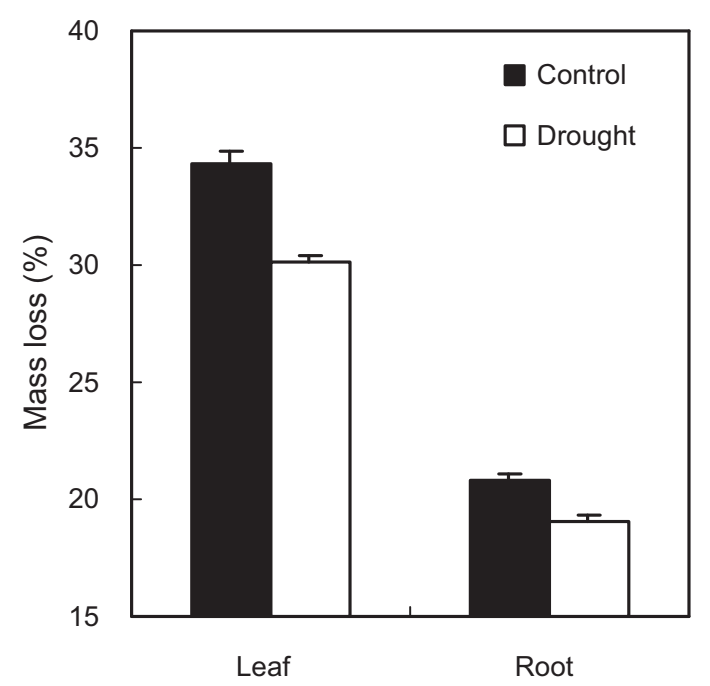

Fig. 4. Interaction between litter type (leaf versus root) and drought on mass loss of root and leaf litter. Bars represent mass loss (mean \pm 1 standard error, $n=5$ ) after 2 months of incubation.

Drought had a significant positive effect on soil mineral $\mathrm{N}$ and $\mathrm{N}$ mineralisation rates across all plant diversity and $\mathrm{N}$ treatments (Table 4, Fig. 6). Nevertheless, drought had no consistent effect on mass of below-ground plant $\mathrm{N}$ (Table 3). Furthermore, impacts of drought on the mass of above-ground $\mathrm{N}$ varied
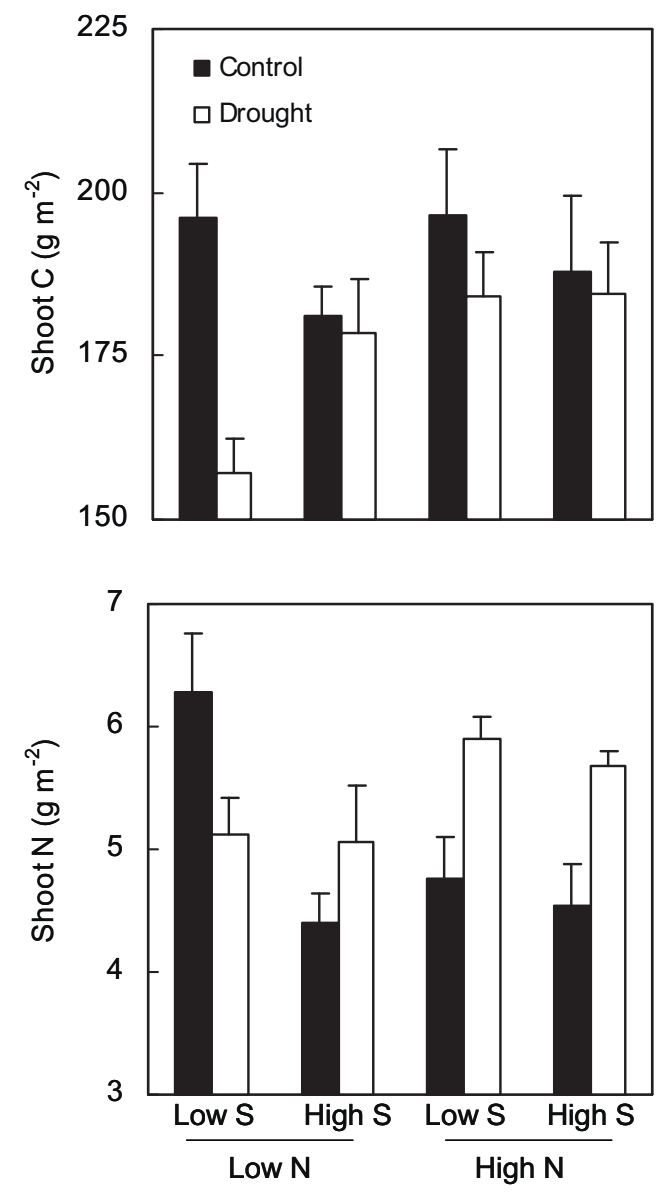

depending on $\mathrm{N}$ treatment (Table 3, Fig. 5). In the high $\mathrm{N}$ treatment, drought increased above-ground plant $\mathrm{N}$ mass whereas in the low $\mathrm{N}$ treatment, no significant effects of drought were observed on above-ground $\mathrm{N}$ mass. Response patterns in above-ground $\mathrm{N}$ mass were almost certainly confounded by significant drought-induced reductions in legume abundance in the low $\mathrm{N}$, low diversity treatment (32.6\% versus $17.3 \%$ in the control and droughted mesocosms, respectively).

\section{Discussion}

\section{Ecosystem responses to drought}

Understanding the patterns and mechanisms of ecosystem stability in a changing environment is critical for sustainable ecosystem management and ecosystem restoration (Hooper et al., 2005). In the present study, we used above-ground and belowground drought responses as a proxy for short-term ecosystem stability, and an indicator of grassland vulnerability to a 100 -year drought event. By constructing species assemblages which conform closely to specific grassland communities, and aligning the date of our final harvests with local management practices, our data provide valuable insights into the short-term impacts of extreme drought for grassland managers and agricultural stakeholders.

As hypothesized, we found that extreme drought was associated with a significant decrease in soil moisture and $\mathrm{CO}_{2}$ fluxes $\left(R_{\text {eco }}\right.$ and $\mathrm{NEE}$ ), as well as reductions in litter decomposition rates and root $\mathrm{C}$ at final harvest ( 4 weeks after experimental drought). However,
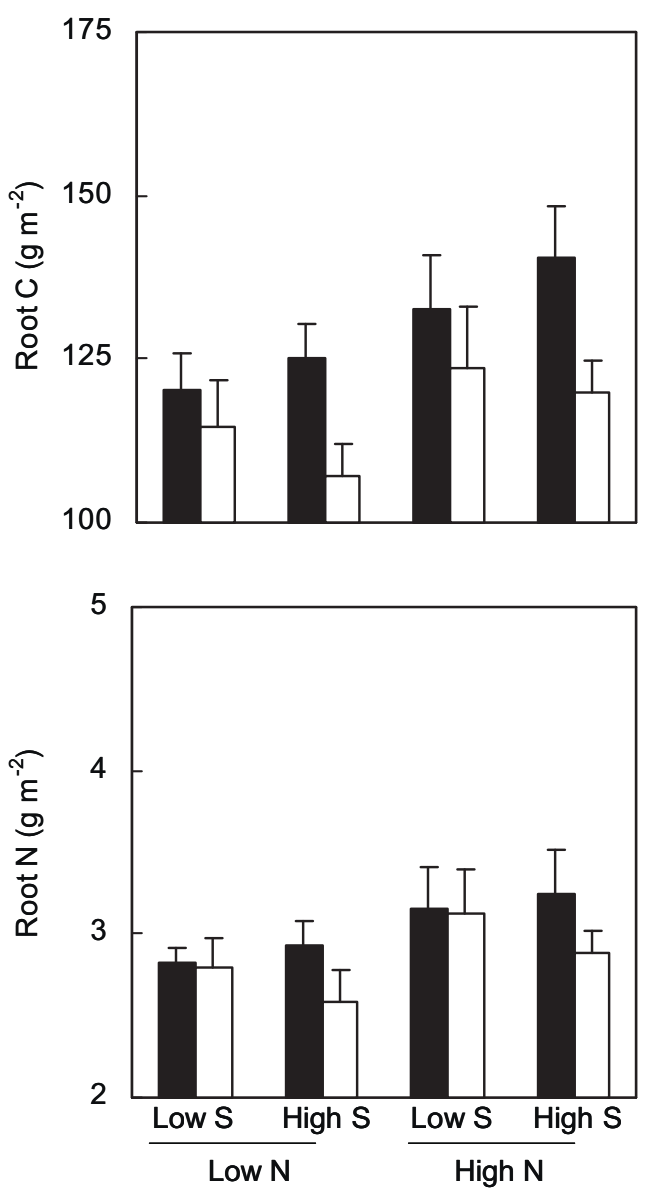

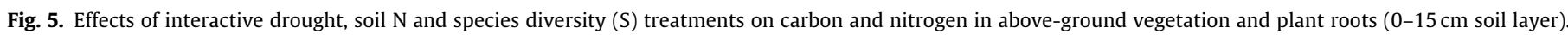
Means and standard errors are presented $(n=5)$. 

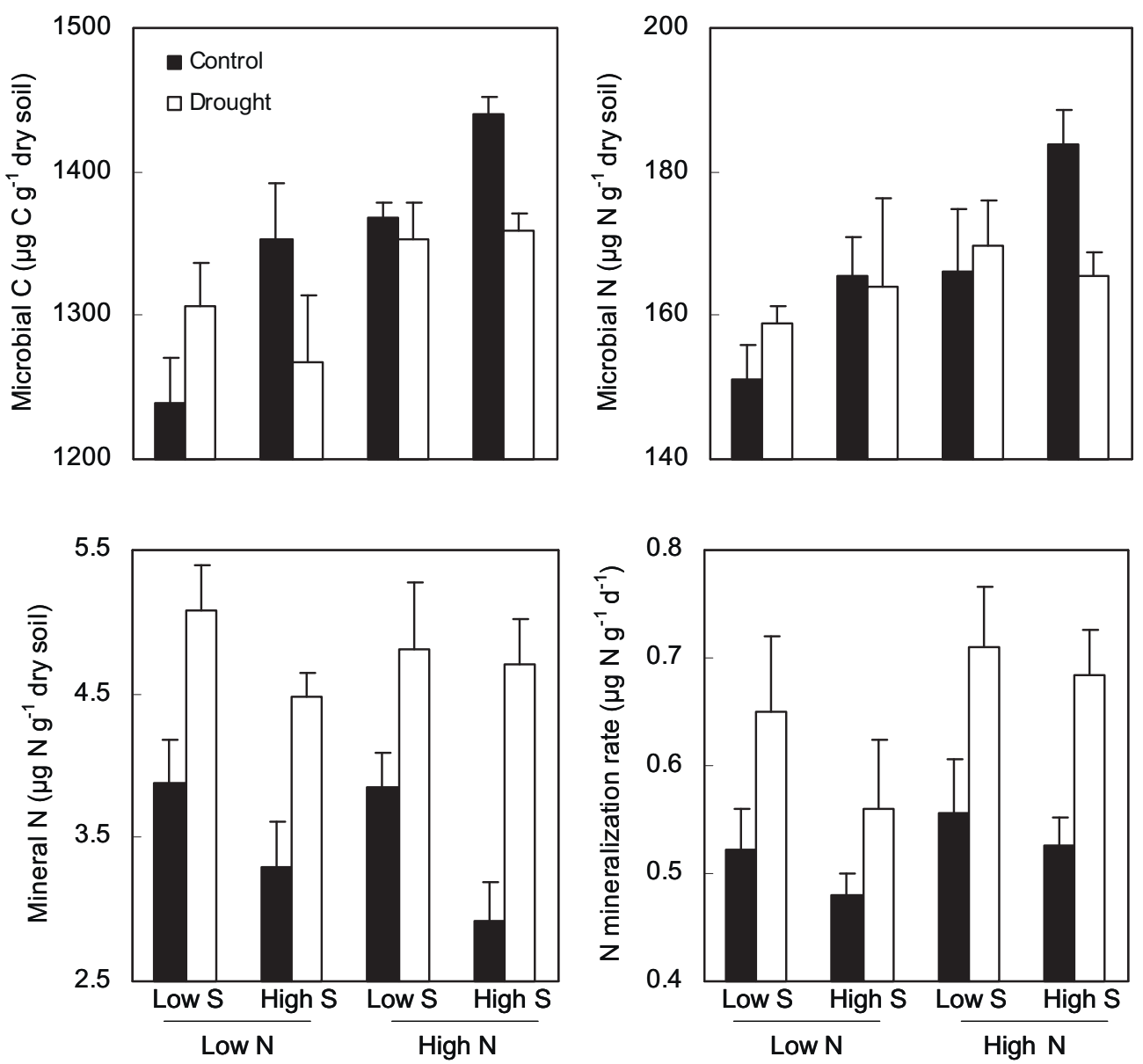

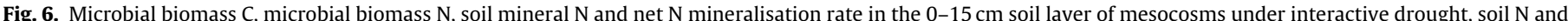
species diversity $(S)$ treatments. Means and standard errors are presented $(n=5)$.

Table 3

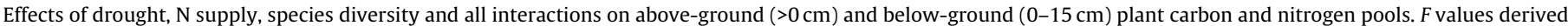
from analysis of variance are shown: significant effects $(P<0.05)$ are shown bold type.

\begin{tabular}{|c|c|c|c|c|}
\hline \multirow[t]{2}{*}{ Effect } & \multicolumn{4}{|l|}{ Variables } \\
\hline & Above-ground $\mathrm{C}$ & Above-ground $\mathrm{N}$ & Root C & Root N \\
\hline Drought & 4.40 & 3.82 & 5.79 & 1.35 \\
\hline $\mathrm{N}$ level & 4.26 & 0.01 & 6.47 & 4.91 \\
\hline Diversity & 0.04 & 7.00 & 0.02 & 0.18 \\
\hline Drought $\times \mathrm{N}$ & 1.89 & 9.23 & 0.11 & 0.01 \\
\hline Drought $\times$ Diversity & 4.35 & 3.33 & 1.56 & 1.13 \\
\hline $\mathrm{N} \times$ Diversity & 0.34 & 2.95 & 0.10 & 0.01 \\
\hline Drought $\times \mathrm{N} \times$ Diversity & 1.48 & 3.33 & 0.01 & 0.01 \\
\hline
\end{tabular}

$\mathrm{DF}_{1,23}$ for all terms except drought $\left(\mathrm{DF}_{1,8}\right) ; n=5$.

Table 4

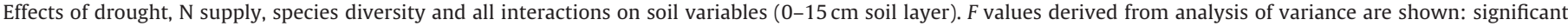
effects $(P<0.05)$ are shown bold type.

\begin{tabular}{|c|c|c|c|c|}
\hline \multirow[t]{2}{*}{ Effect } & \multicolumn{4}{|l|}{ Variables } \\
\hline & Microbial C & Microbial N & Soil inorganic N & $\mathrm{N}$ mineralisation rate \\
\hline Drought & 1.56 & 2.41 & 13.66 & 37.69 \\
\hline N level & 24.34 & 10.72 & 0.30 & 3.35 \\
\hline Diversity & 4.58 & 2.60 & 12.79 & 1.69 \\
\hline Drought $\times \mathrm{N}$ & 1.17 & 0.56 & 0.48 & 0.55 \\
\hline Drought $\times$ Diversity & 9.21 & 6.17 & 1.22 & 0.12 \\
\hline $\mathrm{N} \times$ Diversity & 0.01 & 0.39 & 0.17 & 0.30 \\
\hline Drought $\times \mathrm{N} \times$ Diversity & 1.40 & 0.01 & 1.96 & 0.16 \\
\hline
\end{tabular}

$\mathrm{DF}_{1,23}$ for all terms except drought $\left(\mathrm{DF}_{1,8}\right) ; n=5$. 
drought-induced reductions in $\mathrm{CO}_{2}$ fluxes observed during drought and shortly after rewetting did not persist, and $\mathrm{CO}_{2}$ fluxes showed either complete recovery or overcompensation during the 4-week drought recovery period. These data corroborate previous work on low diversity grassland assemblages which indicate that light use efficiency and maximum NEE show overcompensation in the weeks following drought, largely due to a shift from reproductive to vegetative growth (Mirzaei et al., 2008). At the end of the study, droughted mesocosms showed increases in shoot $\mathrm{N}$, soil inorganic $\mathrm{N}$ and rates of $\mathrm{N}$ mineralisation compared with undroughted mesocosms. This is consistent with drought-induced increases in soil $\mathrm{N}$ cycling rates observed in both field and laboratory experiments elsewhere (White et al., 2004).

Water and soil nutrient retention typically decrease after drought as a result of drought-induced changes to soil structure and soil hydrophobicity which promote preferential flow during rewetting (Muhr et al., 2010). Contrary to expectations, we recorded lower volumes of drainage water from the droughted compared to non-droughted mesocosms following rewetting, with cascading effects on DOC and DON losses. It is likely that observed drought effects were initially driven by high soil water content in the control mesocosms; additional rainfall resulted in significant water seepage from soils close to water-carrying capacity. Towards the end of the experimental period, however, we detected a significant negative correlation between plant biomass and water drainage volumes, indicating that longer-term drought-induced reductions in seepage and DOC/DON leaching losses were maintained by differences in plant water demand. In contrast, DIN losses were poorly correlated with water drainage volumes and showed limited drought responses, suggesting high biological $\mathrm{N}$ demand across treatments during the drought recovery period.

\section{Interactions between species diversity and drought}

In line with the diversity-stability hypothesis, we predicted that our high diversity grassland communities would be better able to buffer the effects of an extreme drought. Our results provide partial support for this idea: (i) $R_{\text {eco }}$ in the high-diversity, droughted mesocosms showed compensatory effects after rewetting; and (ii) above-ground vegetation $\mathrm{C}$ in the high plant diversity treatment showed no significant effects of drought at final harvest, whereas low plant diversity mesocosms showed drought-induced reductions in shoot $\mathrm{C}$. However, we found no diversity $\times$ drought interactions for litter decomposition, soil nutrient leaching losses, or soil fertility. Unlike previous studies (Kahmen et al., 2005; Tilman et al., 2006), we found no evidence that observed patterns in above-ground vegetation $C$ were correlated with variation in below-ground $\mathrm{C}$, or shifts in the abundance of plant functional groups (data not shown). Instead, drought responses in shoot $\mathrm{C}$ were negatively correlated with those of microbial biomass $C$, suggesting that maintenance of shoot $\mathrm{C}$ under drought conditions occurred at the expense of soil microbial biomass (and vice versa).

To our knowledge this is the first study to demonstrate the importance of plant-microbe interactions for the stability of aboveground productivity in model grassland ecosystems under drought. Although the notion that microbial stability plays a key role in the regulation of ecosystem stability is not new (O'Neill, 1976), data coupling both plant and microbial responses to severe drought are scarce. The only two such studies of which we are aware both examined drought effects on low plant diversity ( $\leq 4$ species) assemblages (Wardle et al., 2000; Kreyling et al., 2008), and neither of these found a clear pattern of drought response with plant species diversity or a link between stability of plant productivity and microbial activity. Nonetheless, negative correlations between root biomass and resistance of microbial activity to short-term drying/rewetting have previously been documented for grassland species (Orwin and Wardle, 2005).

The trade-off observed here between stability of above-ground vegetation $C$ storage and microbial biomass may reflect droughtinduced changes in plant-microbial competition for $\mathrm{N}$ across the two grassland community types (Kaye and Hart, 1997; Hodge et al., 2000). Although we do not know the exact mechanisms involved, one possibility is that plants in high-diversity mesocosms are better able to take advantage of drought-induced increases in soil nutrient availability following rewetting compared with plants in low-diversity mesocosms. This assumes that: (i) low-diversity mesocosms have a lower probability of containing drought-tolerant plant species (Yachi and Loreau, 1999); and (ii) labile nutrients in high-diversity mesocosms are rapidly taken up by the vegetation pool at the expense of microbial uptake and population growth. The competitive advantage of plants in high-diversity mesocosms could be further amplified by increased complementarity in $\mathrm{N}$ resource use and/or likelihood of plants with high $\mathrm{N}$ demand (Hooper et al., 2005). Alternatively, droughtinduced shifts in plant/microbial competition for $\mathrm{N}$ could arise if the microbial communities associated with the two grassland communities differ in their sensitivity to drought (Schimel et al., 2007; Gordon et al., 2008). This assumes that drought-sensitive microbial communities in high-diversity mesocosms liberate more nutrients after rewetting. Clearly, further work is needed to confirm the importance of plant-microbial resource partitioning for grassland stability to drought, and to determine whether our findings reflect diversity effects per se or the presence of particular plant species in the high diversity mesocosms.

\section{Interactions between soil $\mathrm{N}$ availability and drought}

Previous work suggests that soil nutrient availability could play an important role in mediating stability of ecosystem processes via changes in above-ground and below-ground plant $\mathrm{C}$ allocation patterns and plant traits (Chapin, 1980; MacGillivray et al., 1995) or plant-soil feedbacks (Manning et al., 2006). However, despite recording higher plant biomass and lower soil moisture levels in the high $\mathrm{N}$ treatment during the study, we found no interaction between $\mathrm{N}$ and drought on $\mathrm{CO}_{2}$ fluxes or $\mathrm{C}$ storage in vegetation, soil and microbial pools. Drought-induced differences in above-ground $\mathrm{N}$ storage in low- and high-N treatments could be explained by shifts in legume abundance. Moreover, we only found a transient drought $\times \mathrm{N}$ interaction on nutrient leaching losses; 2 days after rewetting, the droughted, low $\mathrm{N}$ treatment was associated with increased nutrient retention (DOC, DON, DIN) whereas droughted, high $\mathrm{N}$ mesocosms had increased DIN leaching losses compared to the non-droughted controls. These results suggest that the stability of above-ground and below-ground processes to drought may be relatively insensitive to soil $\mathrm{N}$ availability for our model grassland communities. Of course it is possible that patterns of response of overall stability observed here may be influenced by the lower $C$ allocation to roots in relatively young grassland systems. Whilst similar patterns of stability in plant community structure to drought have been documented in both 'young' $(<2$ years) and 'old' grassland communities (Franck and McNaughton, 1991; Richardson et al., 2010), the importance of plant community age for the stability of grassland ecosystem processes remains unknown.

\section{Conclusions}

Collectively our findings show that, in the short-term, extreme drought has mixed effects on grassland ecosystem processes: 
drought adversely affected root biomass, litter decomposition rates and short-term $\mathrm{CO}_{2}$ fluxes, but increased soil nutrient retention, soil fertility and longer-term $C$ fixation rates. High plant species diversity promoted stability of above-ground vegetation $C$ storage to drought at the expense of soil microbial biomass, which might reflect drought-induced shifts in plant-microbial resource partitioning or microbial community structure. In contrast, soil $\mathrm{N}$ availability had little effect on the short-term stability of ecosystem processes to extreme drought. Our results underline the importance of plant composition for grassland function in a changing environment and emphasize the need for coupling above-ground and below-ground measurements for a mechanistic understanding of grassland stability. Given that extreme events may accelerate system changes and have long-term repercussions on ecosystem function via plant-soil feedbacks and temporal lags, additional work is needed to determine whether the results obtained here translate into longer-term shifts in grassland ecosystem services.

\section{Acknowledgements}

We thank H. Quirk, V. Van Velsen and R.N. Bloor for help setting up the experiment. Thanks also to S. Oakley for use of a PAR sensor, F. Giacomoni for help with final harvests, A. Salcedo and J.L. Ollier for assistance with $\mathrm{CN}$ analyses, and H. Quirk and K. Orwin for technical advice. This study was supported by an INRA-MRI sabbatical fellowship to JMGB.

\section{Appendix A. Supplementary data}

Supplementary data associated with this article can be found, in the online version, at doi:10.1016/j.ppees.2011.12.001.

\section{References}

Austin, A.T., Araujo, P.I., Leva, P.E., 2009. Interaction of position, litter type and water pulses on decomposition of grasses from the semiarid Patagonian steppe. Ecology 90, 2642-2647.

Borken, W., Matzner, E., 2009. Reappraisal of drying and wetting effects on C and N mineralization and fluxes in soils. Global Change Biol. 15, 808-824.

Brookes, P.C., Landman, A., Pruden, G., Jenkinson, D.S., 1985. Chloroform fumigation and the release of soil nitrogen: a rapid direct extraction method to measure microbial biomass nitrogen in soil. Soil Biol. Biochem. 17, 837-842.

Chapin, F.S., 1980. The mineral nutrition of wild plants. Ann. Rev. Ecol. Syst. 11, 233-260.

De Boeck, H.J., Lemmens, C.M.H.M., Bossuyt, H., Malchair, S., Carnol, M., Merckx, R., Nijs, I., Ceulemans, R., 2006. How do climate warming and plant species richness affect water use in experimental grasslands? Plant Soil 288, 249-261.

De Boeck, H.J., Dreesen, F.E., Jassens, I.A., Nijs, I., 2011. Whole-system responses of experimental plant communities to climate extremes imposed in different seasons. New Phytol. 189, 806-817.

De Deyn, G.B., Quirk, H., Zou, Y., Oakley, S., Ostle, N.J., Bardgett, R.D., 2009. Vegetation composition promotes carbon and nitrogen storage in model grassland communities of contrasting soil fertility. J. Ecol. 97, 864-875.

Easterling, D.R., Meehl, G.A., Parmesan, C., Changnon, S.A., Karl, T.R., Mearns, L.O. 2000. Climate extremes: observations, modeling and impacts. Science 289, 2068-2074.

Fierer, N., Schimel, J.P., 2002. Effects of drying-rewetting frequency on soil carbon and nitrogen transformations. Soil Biol. Biochem. 34, 777-787.

Franck, D.A., McNaughton, S.J., 1991. Stability increases with diversity in plant communities: empirical evidence from the 1988 Yellowstone drought. Oikos 62 360-362.

Gilgen, A.K., Buchmann, N., 2009. Response of temperate grasslands at different altitudes to simulated summer drought differed but scaled with annual precipitation. Biogeosciences 6, 5217-5250.

Gordon, H., Haygarth, P.M., Bardgett, R.D., 2008. Drying and rewetting effects on soil microbial community composition and nutrient leaching. Soil Biol. Biochem. 40, 302-311.

Hobbie, S.E., Oleksyn, J., Eissenstat, D.M., Reich, P.B., 2010. Fine root decomposition rates do not mirror those of leaf litter among temperate tree species. Oecologia $162,505-513$.

Hodge, A., Robinson, D., Fitter, A.H., 2000. Are microorganisms more effective than plants at competing for nitrogen. Trends Plant Sci. 5, 304-308.
Hooper, D.U., Chapin, F.S., Ewel, J.J., et al., 2005. Effects of biodiversity on ecosystem functioning: a consensus of current knowledge. Ecol. Monogr. 75, 3-35.

IPCC, 2007. Summary for policymakers. In: Solomon, S., Qin, D., Mannin, M., et al. (Eds.), Climate Change 2007: The Physical Science Basis. Contribution of the Working Group I to the Fourth Assessment Report of the Intergovernmental Panel on Climate Change. Cambridge University Press, UK.

Jentsch, A., Kreyling, J., Beierkuhnlein, C., 2007. A new generation of climate change experiments: events, not trends. Front. Ecol. Environ. 5, 315-324.

Jentsch, A., Kreyling, J., Elmer, M., et al., 2011. Climate extremes initiate ecosystem-regulating functions while maintaining productivity. J. Ecol. 99, 689-702.

Johnson, K.H., Vogt, K.A., Clarck, H.J., Schmitz, O.J., Vogt, D.J., 1996. Biodiversity and the productivity and stability of ecosystems. TREE 11, 372-377.

Kahmen, A., Perner, J., Buchmann, N., 2005. Diversity-dependent productivity in semi-natural grasslands following climate perturbations. Funct. Ecol. 19, 594-601.

Kaye, J.P., Hart, S.C., 1997. Competition for nitrogen between plants and soil microorganisms. TREE 12, 139-143.

Knapp, A.K., Smith, M.D., 2001. Variation among biomes in temporal dynamics of aboveground primary production. Science 291, 481-484.

Kreyling, J., Beierkuhnlein, C., Elmer, M., Pritsch, K., Radovski, M., Schloter, M., Wollecke, J., Jentsch, A., 2008. Soil processes remain remarkably stable after 100-year extreme weather events in experimental grassland and heath. Plant Soil 308, 175-188.

Laurenroth, W.K., Sala, O.E., 1992. Long-term forage production of North American shortgrass steppe. Ecol. Appl. 2, 397-403.

MacGillivray, C.W., Grime, J.P., Team, T.I.S.P., 1995. Testing predictions of the resistance and resilience of vegetation subjected to extreme events. Funct. Ecol. 9, 640-649.

Maestre, F.T., Reynolds, J.F., 2007. Amount or pattern? Grassland responses to the heterogeneity and availability of two key resources. Ecology 88, 501-511.

Manning, P., Newington, J.E., Robson, H.R., et al., 2006. Decoupling the direct and indirect effects of nitrogen deposition on ecosystem function. Ecol. Lett. 9, 1015-1024.

Mirzaei, H., Kreyling, J., Hussain, M.Z., Li, Y., Tenhunen, J., Beierkunlein, C., Jentsch, A., 2008. A single drought event of 100 -year recurrence enhances subsequent carbon uptake and changes carbon allocation in experimental grassland communities. J. Plant Nutr. Soil Sci. 171, 681-689.

Muhr, J., Franke, J., Borken, W., 2010. Drying-rewetting events reduce C and N losses from a Norway spruce forest floor. Soil Biol. Biochem. 42, 1303-1312.

O'Neill, R.V., 1976. Ecosystem persistence and heterotrophic regulation. Ecology 57, $1244-1253$.

Orwin, K.H., Wardle, D.A., 2005. Plant composition effects on belowground properties and the resistance and resilience of the soil microflora to a drying disturbance. Plant Soil 278, 205-221.

Pfisterer, A.B., Schmid, B., 2002. Diversity-dependent production can decrease the stability of ecosystem functioning. Nature 416, 84-86.

Richardson, P.J., Horrocks, J., Larson, D.W., 2010. Drought resistance increases with species richness in restored populations and communities. BAAE 11, 204-215.

Rodwell, J.S. (Ed.), 1998. British Plant Communities: Grasslands and Montane Communities. Cambridge University Press, UK.

Ross, R.J., 1992. Influence of sieve mesh size on estimates of microbial carbon and nitrogen by fumigation-extraction procedures in soils under pasture. Soil Biol. Biochem. 24, 343-350.

Schimel, J., Balser, T.C., Wallenstein, M., 2007. Microbial stress-response physiology and its implications for ecosystem function. Ecology 88, 1386-1394.

Smith, M.D., 2011. The ecological role of climate extremes: current understanding and future prospects. J. Ecol. 99, 651-655.

Sparling, G.P., Feltham, C.W., Reynolds, J., West, A.W., Singleton, P., 1990. Estimation of soil microbial $C$ by a fumigation-extraction method: use on soils of high organic matter content, and re-assessment of the $K_{\mathrm{ec}}$-factor. Soil Biol. Biochem. 22, 301-307.

St. Clair, S.B., Sudderth, E.A., Castanha, C., Torn, M.S., Ackerly, D.D., 2009. Plant responsiveness to variation in precipitation and nitrogen is consistent across the compositional diversity of a California annual grassland. J. Veg. Sci. 20, 860-870.

Tilman, D., 1990. Constraints and trade-offs: towards a predictive theory of competition and succession. Oikos 58, 3-15.

Tilman, D., Reich, P.B., Knops, J.M.H., 2006. Biodiversity and ecosystem stability in a decade-long grassland experiment. Nature 441, 629-631.

Van Peer, L., Nijs, I., Reheul, D., De Cauer, B., 2004. Species richness and susceptibility to heat and drought extremes in synthesized grassland ecosystems: compositional vs physiological effects. Funct. Ecol. 18, 769-778.

Van Ruijven, J., Berendse, F., 2010. Diversity enhances community recovery but not resistance after drought. J. Ecol. 98, 81-86

Verburg, P.S.J., Larsen, J., Johnson, D.W., Schorran, D.E., Arnone III, J.A., 2009. Impacts of an anomalously warm year on soil nitrogen availability in experimentally manipulated intact tallgrass prairie ecosystems. Global Change Biol. 15, 888-900.

Wang, Y., Yu, S., Wang, J., 2007. Biomass-susceptibility to drought in experimental grassland communities. Ecol. Lett. 10, 401-410.

Ward, S.E., Bardgett, R.D., McNamara, N.P., Ostle, N.J., 2009. Plant functional group identity influences short-term peatland ecosystem carbon flux: evidence from a plant removal experiment. Funct. Ecol. 23, 454-462. 
Wardle, D.A., Bonner, K.I., Barker, G.M., 2000. Stability of ecosystem properties in response to aboveground functional group richness and composition. Oikos 89 $11-23$.

White, C.S., Moore, D.I., Craig, J.A., 2004. Regional-scale drought increases potential soil fertility in semiarid grasslands. Biol. Fertil. Soil 40, 73-78.
Yachi, S., Loreau, M., 1999. Biodiversity and ecosystem productivity in a fluctuating environment: the insurance hypothesis. Proc. Natl. Acad. Sci. U.S.A. 96 1463-1468.

Zar, J.H., 1998. Biostatistical Analysis. International edition (NJ). Upper Saddle River $663 \mathrm{p}$. 